\title{
MEASUREMENT ACCURACY INVESTIGATION OF TOUCH TRIGGER PROBE WITH FIVE-AXIS MACHINE TOOLS
}

\begin{abstract}
The touch trigger probe plays an important role in modern metrology because of its robust and compact design with crash protection, long life and excellent repeatability. Aside from coordinate measuring machines (CMM), touch trigger probes are used for workpiece location on a machine tool and for the accuracy assessment of the machine tools. As a result, the accuracy of the measurement is a matter of interest to the users. The touch trigger probe itself as well as the measuring surface, the machine tool, measuring environment etc. contribute to measurement inaccuracies. The paper presents the effect of surface irregularities, surface wetness due to cutting fluid and probing direction on probing accuracy on a machine tool.
\end{abstract}

\section{Introduction}

Users of machine tools seek to integrate touch trigger probe measurements within the machine tool environment so that the machine tool can locate the part, perform self-checks and ultimately inspect the machined part at strategic points throughout the machining of a part. In general, a touch trigger probe provides a binary signal, when contact occurs with the workpiece surface, which is used to trigger readings of the machine's X-, Y- and Z-axis positions. The touch trigger probe temporarily replaces the cutting tool in the machine spindle. On-machine measurement of the workpiece allows one to take corrective actions while the workpiece is still on the machine tool [1]. Thus the accuracy of the measuring device (probe) has significant influence on the part produced.

Cauchick-Miguel and King studied the factors that affect probe accuracy including the approach direction, probe lobing, measuring speed, probe indexing

\footnotetext{
${ }^{1}$ Mechanical Engineering Dept., Polytechnique Montréal, P.O. Box 6079, Station Downtown, H3C $3 A 7$ Montréal (QC), Canada. Email: mdmizanur.rahman@polymtl.ca
} 
angle and spring pressure by measuring a precision spheres [2]. Wozniak et al. considered probe pretravel variation as one of the major sources of probe inaccuracies. They experimentally demonstrated that configuration of the probe, triggering force, stylus length and stiffness influence the probe pretravel variation [3]. Later on, they proposed a new technique for the verification of CMM touch trigger probe accuracy by measuring the distance between a reference point and the triggering point for different directions. The reference point is defined by the axis of rotation of the most stable axis of any rotary table [4]. By using this technique they also showed that the measured object's shape, surface roughness and material stiffness contribute to the inaccuracies caused by a touch trigger probe [5].

Johnson et al. investigated the dynamic error characteristics of touch trigger probes on a CMM and found measurement speed, probe longitude, approach distance, probe latitude, stylus length/stylus tip diameter, probe orientation, operating mode (scanning and non-scanning), scan pitch, preload spring force (gauging force), probe type, and the surface approach angle had an important impact on probe accuracy. They also proposed some solution to avoid such error sources, such as optimizing the measurement speed along with a defined probe spring force and selection of probe type [6].

Fesperman et al. proposed an evaluation method for the standard of numerical control machines' measuring performance assessment furnished with touch trigger probe. Based on the designed tests, probing repeatability, two dimensional (2D) and three dimensional (3D) probing errors as well as the inaccuracies in distinguishing the WCS (workpiece coordinate system) in MCS (machine coordinate system) is also considered for this evaluation method [7]. This work is aimed at creating a baseline for on-machine measurement uncertainty budget data set [8]. Jankowski et al. built a portable setup by using a master artefact with an inner hemisphere for the indirect assessment of the accuracy of the touch-trigger probe. This setup is used to estimate the triggering radius variation in $2 \mathrm{D}$ and $3 \mathrm{D}$ measurements as well as unidirectional repeatability of a touch-trigger probe [9].

All the above works were conducted for CMM probing. On a machine tool, additional factors must be considered. Verma et al. experimentally investigated that machine tool required a particular time of operation to reach its stable operating condition, which is known as warmup period and the machine tool drifts throughout this period. This warmup cycle and the tool change cycle has significant influence on the measurement accuracy of the machine tool [10]. Machining process requires coolant liquid for the cutting process that makes the surfaces wet. Also the surface might not be smooth. Hence, this paper focuses on the external influences that can yield inaccuracies of the probing measurements on a machine tool. Surface irregularities, wetness effect, repeatability of the probe and equivalent probe lobing are experimentally evaluated. 


\section{Measurement methods and results}

For the tests, the table of a five axis WCBXFZYT horizontal machine tool is probed as shown in Fig. 1 with a Renishaw machine touch trigger probe MP700 used with a $100 \mathrm{~mm}$ stylus. Four different test procedures have been followed.

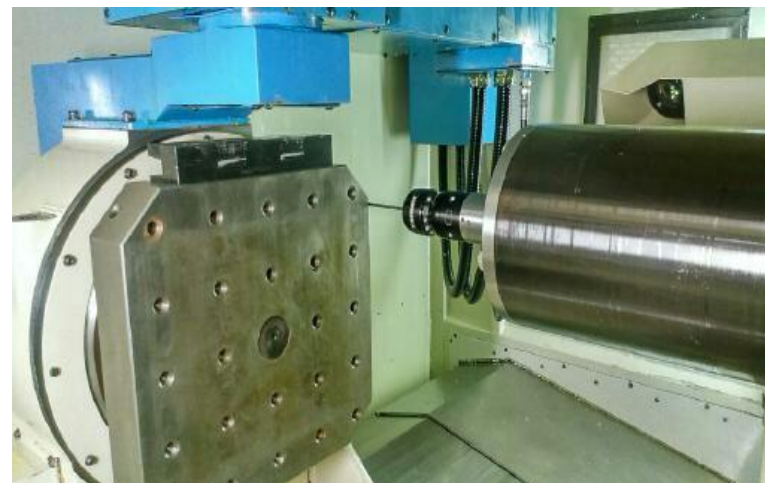

Fig. 1. Probing on a WCBXFZYT machine tool

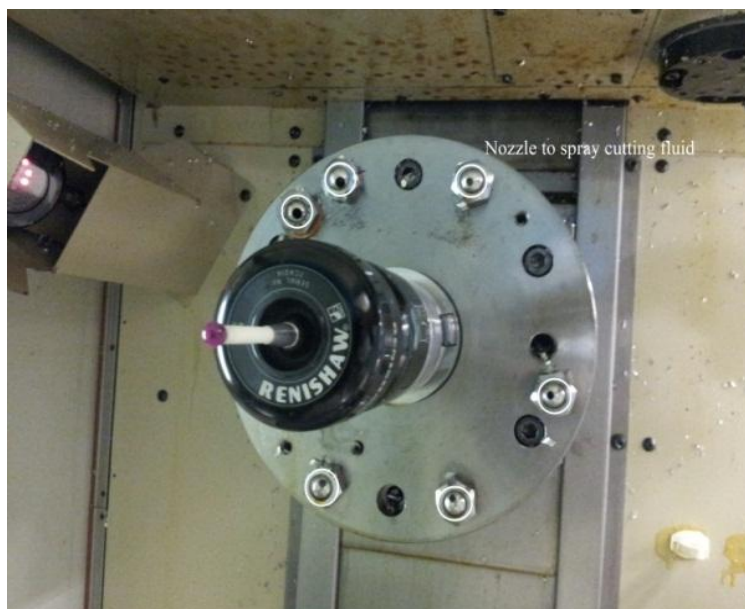

Fig. 2. Spindle with nozzle to spray cutting fluid holding the probe

In procedure I, the unidirectional repeatability of the probe is evaluated by measuring a surface point 300 times in X-, Y-, Z-, 2D- (an inclined XY plane $45^{\circ}$ with the horizontal axis) and 3D-directions (all the linear axes need to move simultaneously). The unit normal vector for the surface point along the $\mathrm{X}$-axis,

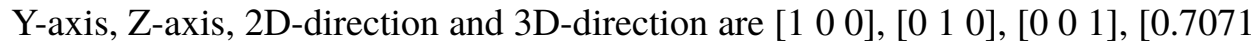
0.70710 ] and [0.4830 0.25880 .8365 ], respectively. The 3D orientation is obtained by rotating $\mathrm{B}$-axis by $60^{\circ}$ and $\mathrm{C}$-axis by $30^{\circ}$ which requires simultaneous movement 
of the machine tool's X-, Y- and Z-axis. The surface is cleaned and dried before the measurements commence.

In Procedure I, total time required for 300 probing with the respective direction is $1 \mathrm{H} 45 \mathrm{M}$ approximately with the full retraction of the probe in Z-axis by $300 \mathrm{~mm}$ after each probing. Fig. 3 shows the presence of a drift for an unknow reason although thermal drift of the machine is suspected. Table 1 shows the results for the Procedure I (unidirectional repeatability of the probe).

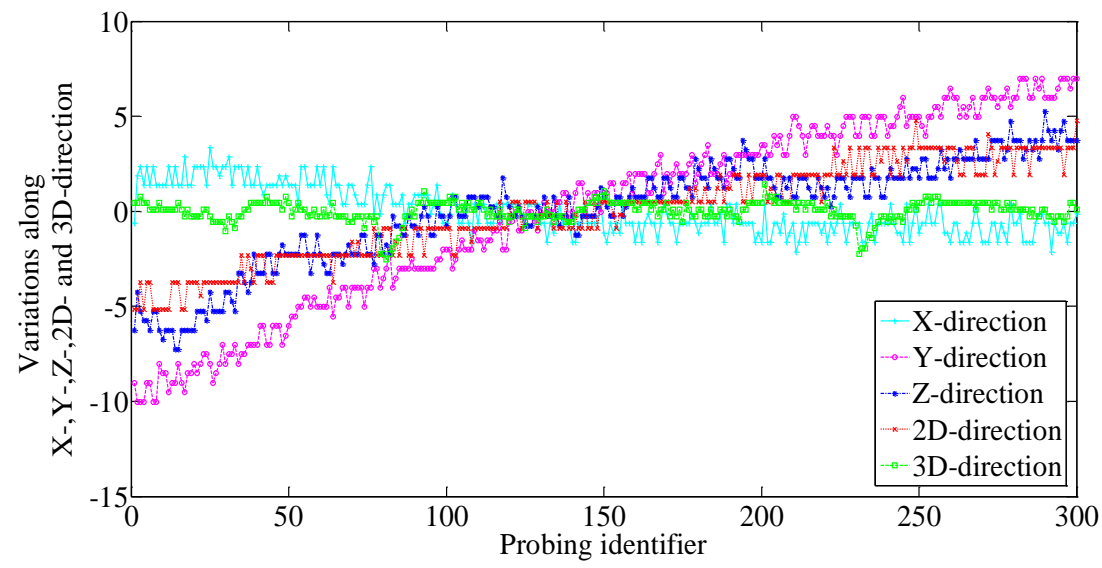

Fig. 3. Procedure I (Unidirectional repeatability)

Table 1.

Range and standard deviation of the probing measurements for 300 repetitions in each of the selected directions

\begin{tabular}{|c|c|c|c|c|c|}
\hline & $\mathrm{X}$ & $\mathrm{Y}$ & $\mathrm{Z}$ & $2 \mathrm{D}$ & $3 \mathrm{D}$ \\
\hline Range $(\mu \mathrm{m})$ & 5.5 & 17.0 & 12.5 & 9.9 & 3.9 \\
\hline Standard deviation $(\mu \mathrm{m})$ & 1.2 & 4.9 & 2.7 & 2.5 & 0.6 \\
\hline
\end{tabular}

The drift could be responsible for the larger variation range of Y-, Z- and 2D-directional measurements. The standard deviation of the measurement in 3D direction is unexpectedly lower primarily because no drift is apparent.

To remove the effect of the drift on the statistical results, pooled standard deviation is calculated for these five directional measurement. For pooled standard deviation calculation, 12 small windows of 25 probings are defined. From these 12 populations, the pooled standard deviation is calculated by using the following formula:

If the populations are indexed as $i=1,2 \ldots m$, then the pooled variance $s_{p}^{2}$ can be estimated by the mean of the variances $s_{i}^{2}$

$$
s_{p, k}^{2}=\frac{\sum_{i=1}^{m}\left(n_{i}-1\right) s_{i, k}^{2}}{\sum_{i=1}^{m}\left(n_{i}-1\right)}
$$


where $n_{i}$ is the sample size of population $i$ and $k$ refers to the X-, Y-, Z-, 2Dand 3D-directions. The pooled standard deviations are given in Table 2. Hence, a significant reduction in the calculated measurement repeatability is gained, which confirms the significant contribution of the observed drift on the standard deviation of the measurements.

Table 2.

Pooled standard deviation for a window of 25 probing measurements based on the probing measurements for 300 repetitions in each of the selected directions

\begin{tabular}{|l|c|c|c|c|c|}
\hline & $\mathrm{X}$ & $\mathrm{Y}$ & $\mathrm{Z}$ & $2 \mathrm{D}$ & $3 \mathrm{D}$ \\
\hline Pooled standard deviations $(\mu \mathrm{m})$ & 0.63 & 0.59 & 0.63 & 0.64 & 0.46 \\
\hline
\end{tabular}

In procedure II, surface wetness effect on probing is assessed by measuring a single surface point in the Z- and 3D- directions. Procedure II includes four different approaches, named A, B, C and D. For Approach A, a surface point with the local surface normal aligned with the machine Z-axis is measured 600 times. For the first 100 touches the surface is dry and clean, for the second 100 touches the cutting fluid (4-6\% of CIMSTAR 60 semi-synthetic metal working fluid added to water) is sprayed manually on the surface to make it wet and this cycle is repeated for the remaining 600 measurements. Approach B is similar to Approach A but instead of manually wetting the surface the machines' own system (Fig. 2) is used to apply the cutting fluid on the surface. The cutting fluid passes through the machine spindle to the targeted surface area.

In Approach C, the same surface point as approach A and B is measured 600 times without using cutting fluid and the surface is kept clean and dry. Finally, in Approach D a surface point is measured with its normal at an oblique 3D angle of the machine tool for 600 times but with the same manner than Approach A. Fig. 4 shows the measurement variation over 600 probing for Approach A, B, C

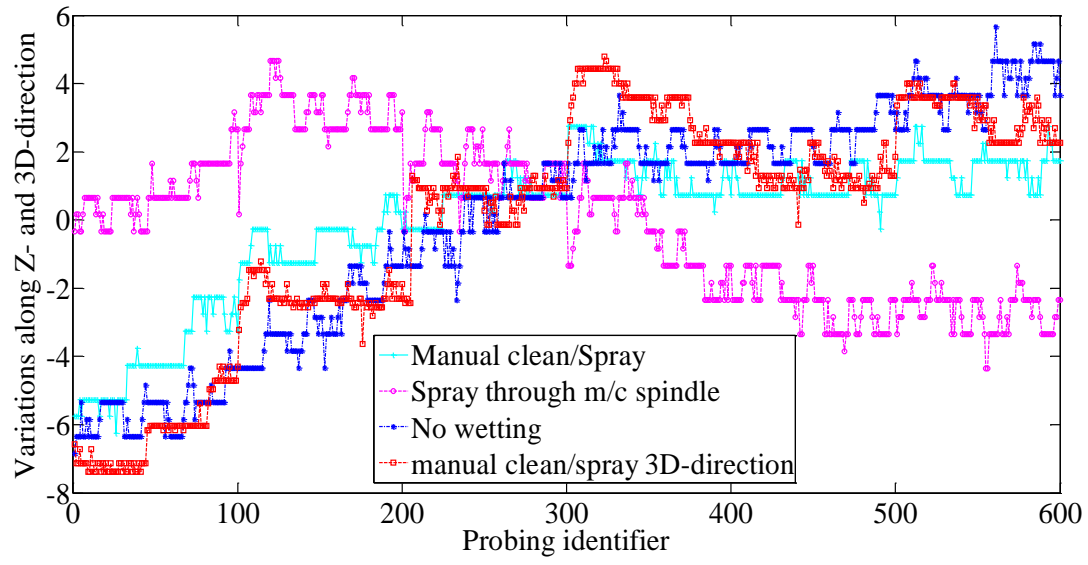

Fig. 4. Procedure II (Approaches A, B, C and D) 
Range and standard deviation for all four approaches in Procedure II

\begin{tabular}{|c|c|c|c|c|}
\hline & Approach A & Approach B & Approach C & Approach D \\
\hline Range $(\mu \mathrm{m})$ & 9.0 & 9.0 & 12.5 & 12.2 \\
\hline Standard deviation $(\mu \mathrm{m})$ & 2.1 & 2.3 & 3.4 & 3.5 \\
\hline Pooled Standard Deviations & 0.53 & 0.8 & 0.6 & 0.63 \\
\hline
\end{tabular}

and D. Total time required for the measurements of each Approach is $1 \mathrm{H} 53 \mathrm{M}$ approximately.

Fig. 4 shows that the results seem to be stabilized after 300 probing for approach A, C and D. For Approach B, the cutting fluid was sprayed through the machine spindle, as shown in Fig. 2, which may cause thermal effects. Plateaus corresponding to the dry and wet cycles are apparent for Approach D only.

Procedure III is for surface irregularity assessment. A $5 \times 5$ spatial grid of 2 by $2 \mathrm{~mm}$ total size with $n=25$ regularly spaced points $P_{i}, i=1$ to $n$, measured along direction $k$ with $k=\mathrm{X}, \mathrm{Y}, \mathrm{Z}, 2 \mathrm{D}$ and $3 \mathrm{D}$. The grid is measured $j=1$ to $m$ times, with $m=19$, for the respective direction hence each point on the grid is revisited $m$ times. Then, the effect of surface irregularities is observed by calculating the mean of each point $i$ and for a specific direction $k, \widehat{P}_{i, k}$, over all $m$ cycles. By doing this, the effect of repeatability and drift can be removed and the graphical representation of the surface irregularity effect is given in Fig. 5. For an indirect machine tool inspection technique like [11], the measured surface can influence the overall measurement inaccuracies as measurements are conducted directly on the machine tool table.

Grid measurement cycle starts with measuring the spatial grid along the Xdirection followed by the Y-, Z-, 2D- and 3D-directions. The means $\widehat{P}_{i, k}$ over all $m$ cycles for a particular direction $k$ is

$$
\widehat{P}_{i, k}=\frac{1}{m} \sum_{j=1}^{m} P_{i, j, k} .
$$

The standard deviation of the $n=25$ grid points means is then calculated for each respective direction

$$
S_{k}^{2}=\sum_{i=1}^{n} \frac{\left(\widehat{P}_{i, k}-\widehat{T}_{k}\right)^{2}}{n-1}
$$

where $\widehat{T}_{k}=\frac{1}{n} \sum_{i=1}^{n} \widehat{P}_{i, k}$.

Table 4 shows the range of the $\widehat{P}_{i, k}$ and standard deviations of $\widehat{P}_{i, k}$ along the $k$ directions. It shows the measurements variation attributed to surface irregularities. The probing in Z- and 3D-directions is shows the largest variations with [range, standard deviation] of $[3.9,0.97] \mu \mathrm{m}$ and $[7.0,1.7] \mu \mathrm{m}$ respectively. 

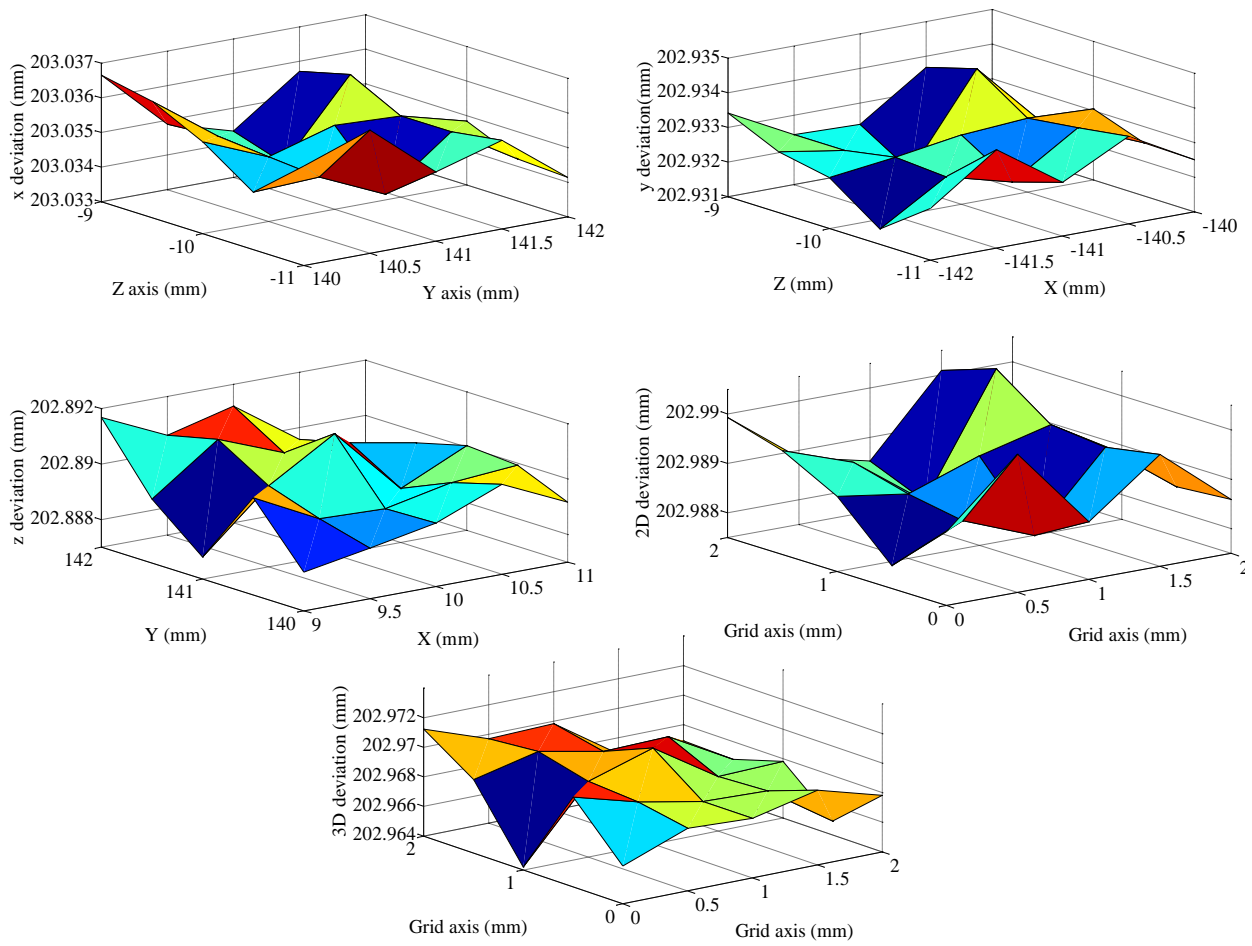

Fig. 5. Effect of surface irregularities on probing of a 2 by $2 \mathrm{~mm}$ spatial grid along the X-, Y-, Z-, 2D- and 3D-directions

Table 4.

Range and standard deviation of the $5 \times 5$ spatial grid probing

\begin{tabular}{|c|c|c|c|c|c|}
\hline & $\mathrm{X}$ & $\mathrm{Y}$ & $\mathrm{Z}$ & $2 \mathrm{D}$ & $3 \mathrm{D}$ \\
\hline Range $(\mu \mathrm{m})$ & 2.9 & 2.7 & 3.9 & 2.5 & 7.0 \\
\hline Standard deviation $(\mu \mathrm{m})$ & 0.86 & 0.68 & 0.97 & 0.73 & 1.7 \\
\hline
\end{tabular}

If we look closer at the individual grid point analysis as given in Table 5 and Fig. 6 (a, b, c, d and e), the measurements are affected by surface irregularities mostly in X-and 3D-direction by a maximum standard deviation of 5.3 and $6.1 \mu \mathrm{m}$ (Table 5). As mentioned earlier, there is a drift affecting the measurement results for the first hour. Hence, the X- and 3D- direction can also be affected by this drift, which results in a larger variation in the measurements. The measurement time is 7 hours and 30 minutes (approximately) and the machine keeps drifting until a stable operating conditionwhen the machine variability shows no particular patternlower. Random variation in 3D-probing has been observed and the reason is unknown. Pooled standard deviaitons are calculated to isolate the variablity. The pooled standard deviation in 3D-probing is $0.95 \mu \mathrm{m}$ which is noticeably smaller. 
Individual standard deviation for each grid point

\begin{tabular}{|c|c|c|c|c|c|}
\hline Grid Points ID & $\mathrm{X}(\mu \mathrm{m})$ & $\mathrm{Y}(\mu \mathrm{m})$ & $\mathrm{Z}(\mu \mathrm{m})$ & $2 \mathrm{D}(\mu \mathrm{m})$ & $3 \mathrm{D}(\mu \mathrm{m})$ \\
\hline 1 & 5 & 2.6 & 1.7 & 2.3 & 5.5 \\
\hline 2 & 4.9 & 2.5 & 1.6 & 2.2 & 1.2 \\
\hline 3 & 5.1 & 2.6 & 1.9 & 2.1 & 6.1 \\
\hline 4 & 5.2 & 2.4 & 1.7 & 2.3 & 1.2 \\
\hline 5 & 5.1 & 2.5 & 2 & 2.2 & 1.1 \\
\hline 6 & 5.1 & 2.3 & 1.7 & 2.2 & 1.2 \\
\hline 7 & 5.2 & 2.3 & 2 & 2.1 & 1.3 \\
\hline 8 & 4.9 & 2.5 & 1.7 & 2.3 & 1.3 \\
\hline 9 & 5.2 & 2.4 & 1.7 & 2.1 & 1.2 \\
\hline 10 & 5.2 & 2.3 & 1.9 & 2.3 & 1.2 \\
\hline 11 & 5.2 & 2.2 & 1.8 & 2.2 & 1.1 \\
\hline 12 & 5.1 & 2.3 & 1.8 & 2.3 & 1.1 \\
\hline 13 & 5.1 & 2.3 & 1.9 & 2.2 & 1.7 \\
\hline 14 & 5.1 & 2.4 & 1.8 & 2.2 & 1.1 \\
\hline 15 & 5.1 & 2.5 & 1.8 & 2.2 & 1 \\
\hline 16 & 5.1 & 2.5 & 1.8 & 2.2 & 1.1 \\
\hline 17 & 5.3 & 2.6 & 1.8 & 2.2 & 0.9 \\
\hline 18 & 5.2 & 2.6 & 1.9 & 2.2 & 1 \\
\hline 19 & 5.1 & 2.5 & 1.9 & 2.1 & 1 \\
\hline 20 & 5.1 & 2.8 & 1.8 & 2.4 & 3.9 \\
\hline 21 & 4.9 & 2.8 & 1.6 & 2.2 & 1 \\
\hline 22 & 4.9 & 2.9 & 1.6 & 2.2 & 5.5 \\
\hline 23 & 4.9 & 2.6 & 1.7 & 2.2 & 1.5 \\
\hline 24 & 4.8 & 2.6 & 1.6 & 2.2 & 3.7 \\
\hline 25 & 4.7 & 2.7 & 1.4 & 2.3 & 1.4 \\
\hline Maximum & 5.3 & 2.9 & 1.9 & 2.4 & 6.1 \\
\hline Minimum & 4.7 & 2.3 & 1.4 & 2 & 0.92 \\
\hline $\begin{array}{c}\text { Pooled } \\
\text { Standard } \\
\text { Deviations }\end{array}$ & 5.1 & 2.4 & 1.8 & 2.1 & 0.95 \\
\hline
\end{tabular}

To observe the effect of the machine state on the grid measurements, a random grid points are considered and a typical trend of measurement variation is given in Fig. 6. The X-axis measurements are affected the most for first and second cycle by approximately $20 \mu \mathrm{m}$ while the measurements variation along other direction remains below $10.0 \mu \mathrm{m}$ (approximately) The grid measurement started in the morning with the machine's cold state hence machine hysteresis as well as the machine's state change can be responsible for the drift on X-axis measurements.

In Procedure III, surface irregularity test was carried out in the machine tool hence the machine tool itself can contribute to the measurement variability. To iso- 


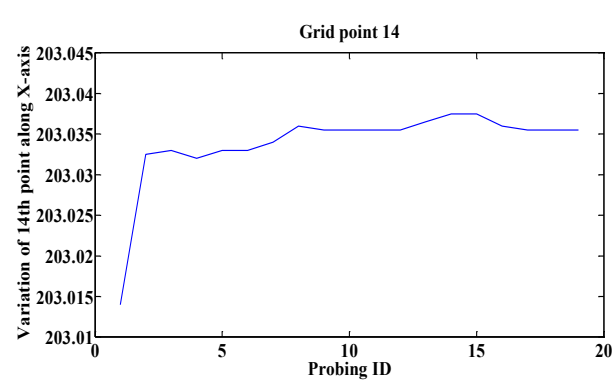

(a)

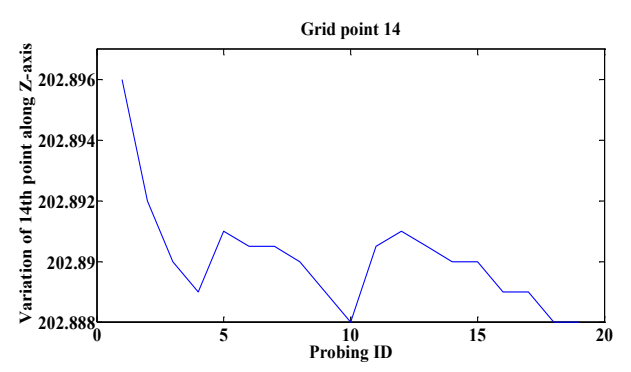

(c)

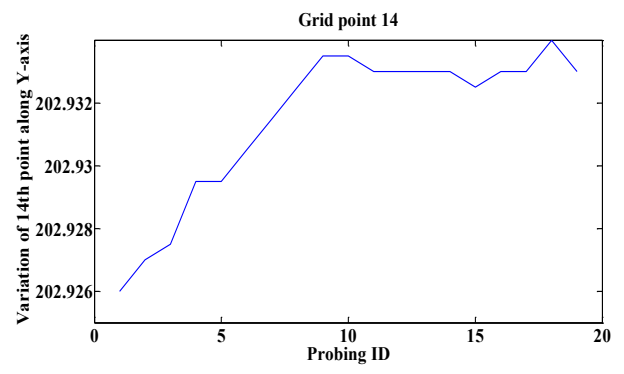

(b)

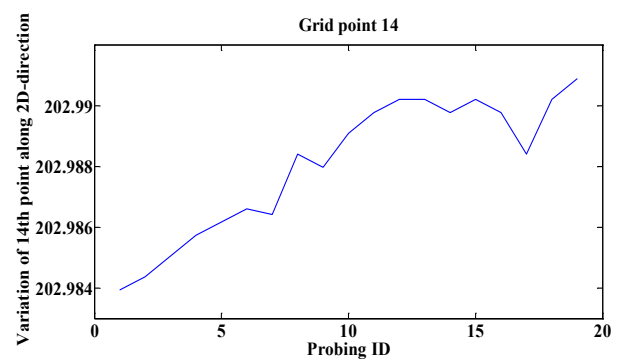

(d)

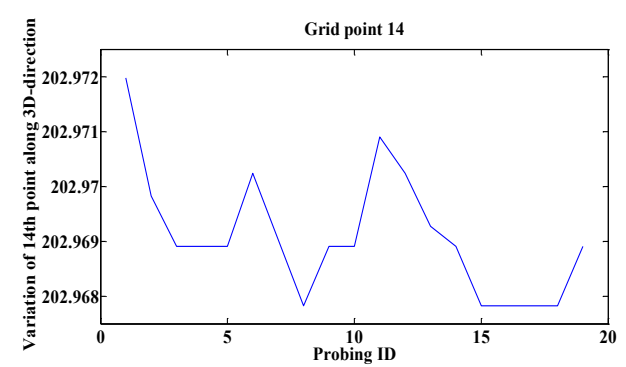

(e)

Fig. 6. A typical trends for spatial grid measurement along X-, Y-, Z-, 2D- and 3D- direction (14th grid point) denoted by a, b, c, d and e respectively. As the spatial grids measurement repeats for 19 times hence the point is measured for 19 times. The variations are in $\mathrm{mm}$

late the effect of the surface on the measurements, the machine table was measured on an accurate Coordinate Measuring Machine (CMM). To do so, six different spatial grids of $0.2 \mathrm{~mm} 0.2 \mathrm{~mm}$ are defined that represents typical surface quality regions with surface normals along X-, Y- and Z- direction as illustrated in Fig. 7. One spatial grid at both positive and negative $\mathrm{X}$ - and $\mathrm{Y}$-direction and two on the negative $\mathrm{Z}$-axis direction since the probe has only negative $\mathrm{Z}$ approach capability. Renishaw PH10M probe is used with a $50 \mathrm{~mm}$ long styli and $8 \mathrm{~mm}$ diameter stylustip and the measuring speed is $300 \mathrm{~mm} / \mathrm{m}$.

Each grid measurements was repeated three times. The average of each point measurement is used to calculate the range and the standard deviation of the measurement variation in each measuring direction. Fig. 7 and Fig. 8 show the 


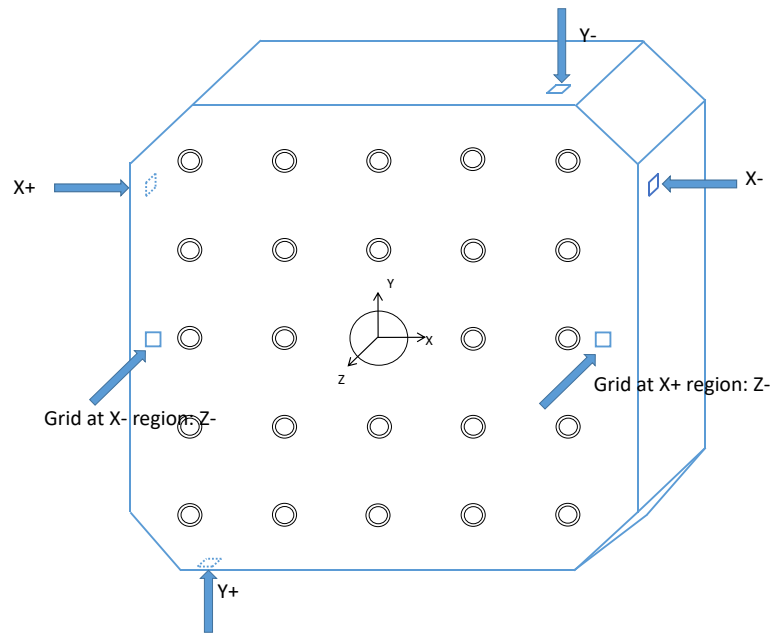

Fig. 7. Spatial grid probing on a CMM (grid size is $200 \mu \mathrm{m} \times 200 \mu \mathrm{m}$ )

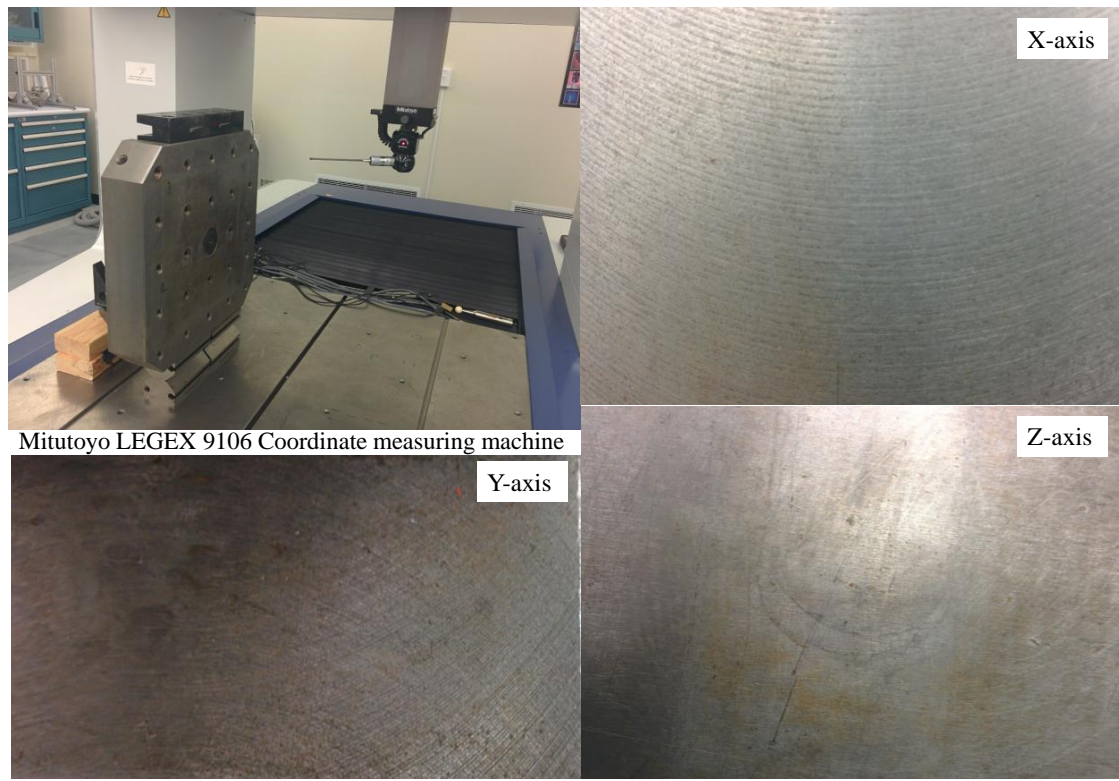

Fig. 8. The Coordinate Measuring Machine (CMM) and surface quality at X-, Y- and Z-direction

location, direction and the quality of the measured surface and Table 6 shows the results.

The range and standard deviation of $\mathrm{X}$ - and Y-axis measurements in Table 4 and Table 6 are similar in size, but for the Z-axis measurements the CMM results show much less variation; about $1 \mu \mathrm{m}$ on the CMM instead of 3 on the machine tools. Fig. 9 shows the variation of the measurements for the six different spatial grid as shown in Fig. 7. 
Table 6.

The range and standard deviations of six spatial grid probing in CMM

\begin{tabular}{|c|c|c|c|c|c|c|}
\hline & $\mathrm{X}+$ & $\mathrm{X}-$ & $\mathrm{Y}+$ & $\mathrm{Y}-$ & $\mathrm{Z}$ (in X+ region) & $\mathrm{Z}$ (in X- region) \\
\hline Range $(\mu \mathrm{m})$ & 3.13 & 3.23 & 2.97 & 2.00 & 1.07 & 1.27 \\
\hline Standard deviation $(\mu \mathrm{m})$ & 0.71 & 0.91 & 0.94 & 0.53 & 0.34 & 0.33 \\
\hline
\end{tabular}

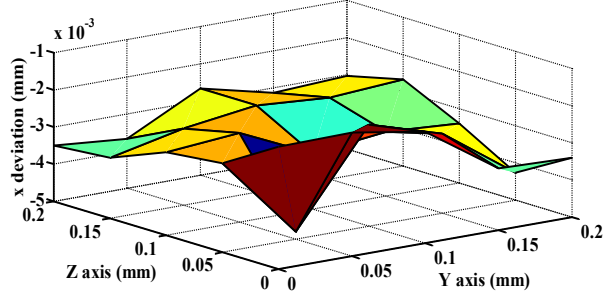

(a)

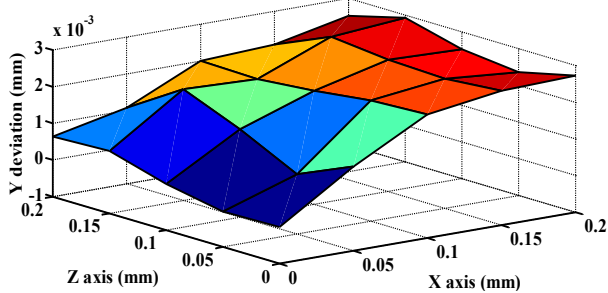

(c)

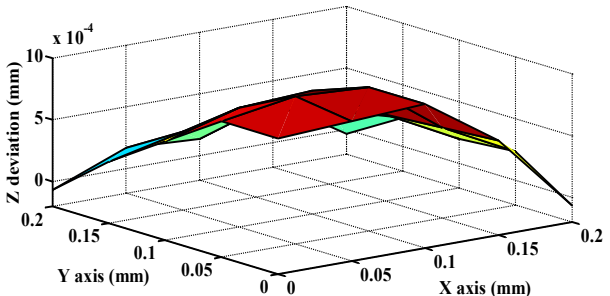

(e)

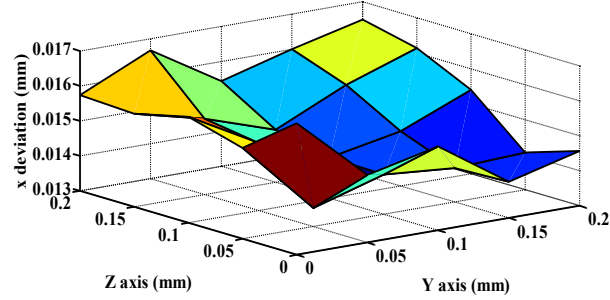

(b)

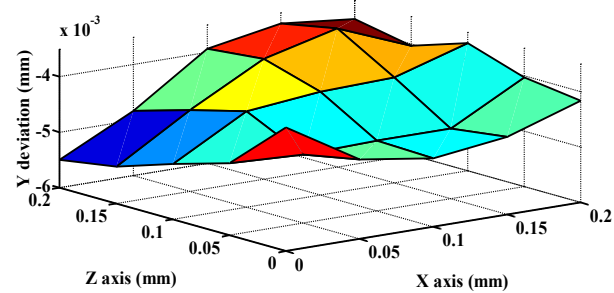

(d)

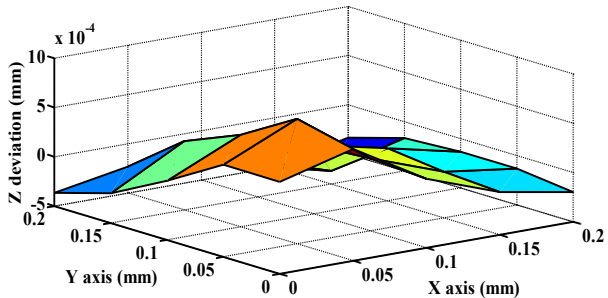

(f)

Fig. 9. Surface irregularity effect on a $200 \mu \mathrm{m} 200 \mu \mathrm{m}$ spatial grid. a) Negative X-probing, b) positive X-probing, c) positive Y-probing, d) negative Y-probing, e) negative Z-probing in X+ region and $\mathrm{f}$ ) negative $\mathrm{Z}$-probing in $\mathrm{X}$ - region of the artefact

Surface irregularity analysis by scanning probe:

A scanning probe Mitutoyo MPP-300 is used to scan a $15 \mathrm{~mm}$ by $15 \mathrm{~mm}$ spatial grid in the X- and Y-direction as shown in Fig. 7 in order to observe the effect of surface irregularities. Research shows that [2], higher measuring speed affects the probe accuracy thus the speed of scanning was kept low at $120 \mathrm{~mm} / \mathrm{m}$. Since the surface in the Z-direction is polished and CMM tests shows that it has negligible contribution only the grid in the $\mathrm{X}$ - and Y-directions are considered for this test.

Fig. 10 shows the scanning probing is in operation on a Legex 910 coordinate measuring machine and Table 7 shows the results of the measurements. Results 


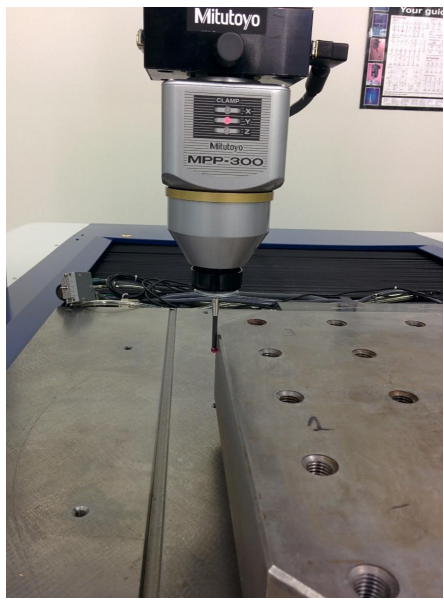

Fig. 10. Mitutoyo MPP-300 scanning probe to measure a $15 \mathrm{~mm}$ by $15 \mathrm{~mm}$ spatial grid on the CMM

Table 7.

Range and standard deviations of six spatial grid obtained by a Mitutoyo MPP-300 scanning probe on $\mathrm{CMM}$

\begin{tabular}{|c|c|c|c|c|}
\hline & $\mathrm{X}+$ & $\mathrm{X}-$ & $\mathrm{Y}+$ & $\mathrm{Y}-$ \\
\hline Range $(\mu \mathrm{m})$ & 3.67 & 6.27 & 2.58 & 3.66 \\
\hline Standard deviation $(\mu \mathrm{m})$ & 0.85 & 1.49 & 0.62 & 0.84 \\
\hline
\end{tabular}

show that, the grid on the $-\mathrm{X}$ direction has maximum standard deviation of 1.49 $\mu \mathrm{m}$.

Procedure IV focused on the effect of the probe and machine. Systematic lobing of the probing results is estimated by probing a precision sphere with a sphericity of $1.6 \mu \mathrm{m}$. The on machine tool probing is done every 30 degrees longitudinally and every 10 degree latitudinally. Then, a sphere is fitted to the measurements. The maximum and minimum residuals, out of sphericity as well as the standard deviation of the residuals, are $4.71,-3.37,8.1$ and $1.7 \mu \mathrm{m}$, respectively.

Fig. 11(b) shows that there is an elliptical trend over the residuals with two visible lobes also visible in Fig. 11 (c and d). This error can be the combined effect of the probe, sphere and the machine itself

\section{Discussion}

Repeated measurements of a single surface point shows that the measurement varies during the warmup cycle (Fig. 3) and significantly affect the repeatability (Table 1). Maximum variation is observed in Y-directional measurements with a range of $17 \mu \mathrm{m}$ and standard deviation of $4.9 \mu \mathrm{m}$. Pooled standard deviation is calculated to remove the effect of the drift and isolate the probe's directional repeatability error which was found to be below $1 \mu \mathrm{m}$ (Table 2). In an industrial 


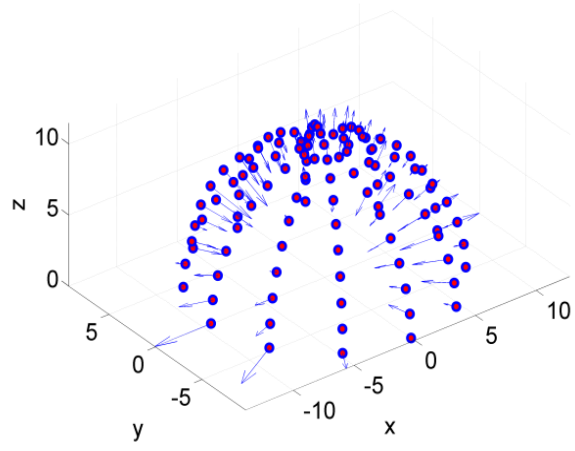

(a)

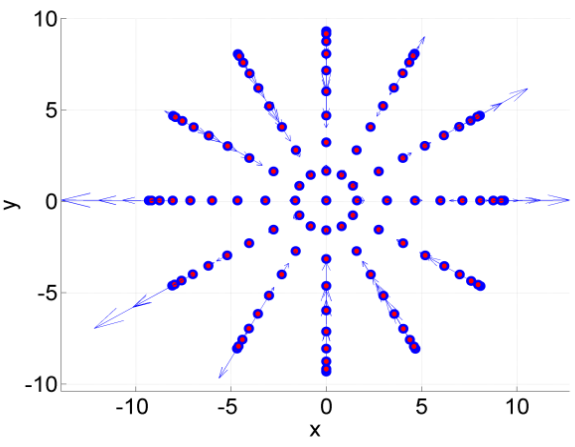

(b)

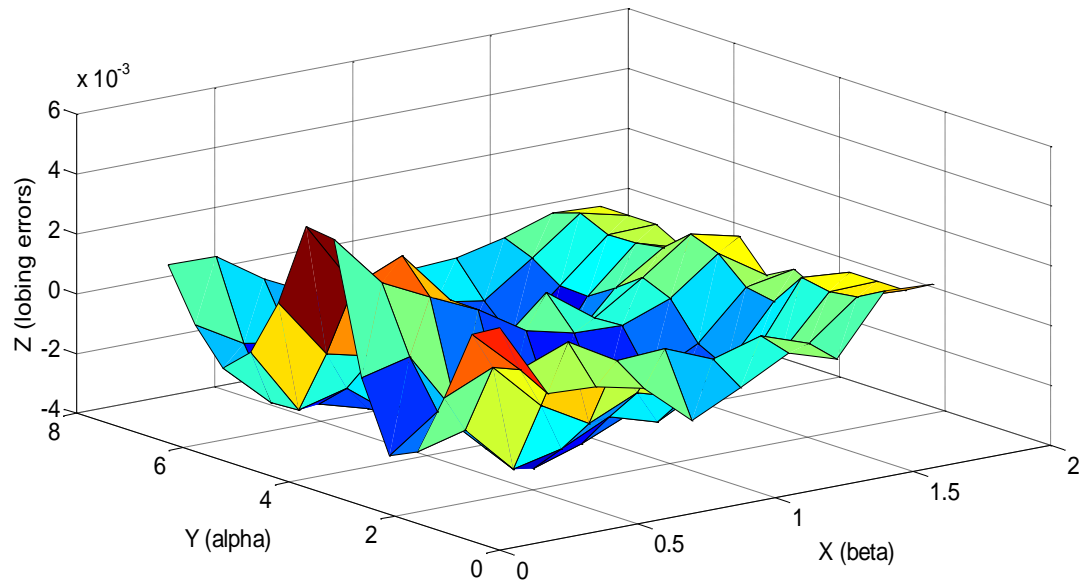

(c)

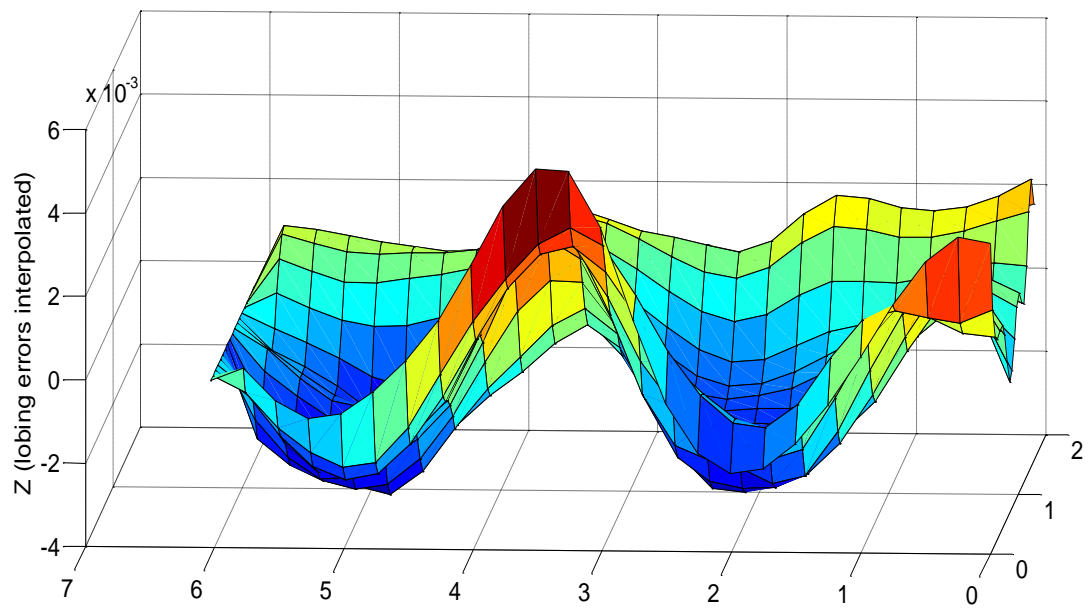

(d)

Fig. 11. Residuals for a sphere probing (1000x) (a) and (b), probe lobing error (c) and interpolated lobing error (d) 
environment, manufacturer uses cutting fluid during the time of operation which is sprayed through the machine tool spindle. The surface of the artefact gets wet when the cutting fluid is used and this might also affect the measurements. The effect of the surface wetness in $1 \mathrm{D}$ probing and $3 \mathrm{D}$ probing is found not to have a significant influence on the measurement results. Machine tool's cutting fluid spraying system might change the thermal state of the spindle during the measurements (Fig. 4), but pooled standard deviations are calculated to isolate this effect from the measurements (Table 3). The artefact used in this work has different surfaces and their quality are also different. The difference is visible in Fig. 8, where the surface on the X-and Y-plane are rougher than the surface on the Z-axis. Surface measurement in the machine tool might be affected by the machine's drift, geometric errors or even the probe errors. CMM measurement of the surface can isolate those influence and provide better picture of the surface irregularity effect on the measurements. However, for additional justification, a scanning probe is used to measure the typical surface of the X-and Y-axis (most irregular) and found good agreement between the grid measurements using Renishaw PH10M touch probe and Mitutoyo MPP-300 scanning probe. The touch probe itself has a significant lobing error. Therefore, the manufacturers must have the knowledge of these error sources and their influence on the measurement is essential when the inspection is done using indirect techniques involving touch probe measurements.

\section{Conclusions}

The influence of the probe, the machine, as well as the measurement environment on the probing results was studied experimentally both on the machine tool and on a CMM. Results on the machine tool show that there is a drift of approximately $10 \mu \mathrm{m}$ for the first hour while the measurements are performed. Surface irregularities are the major contributor to the inaccuracy of the probing when the probe approaches in the Z- and 3D-directions with deviation ranges of 3.9 and $7 \mu \mathrm{m}$ in the machine tool while the CMM measurements shows that surface on X-and Y-axis contribute the most (3.23 and $2.97 \mu \mathrm{m})$. Since the measurement on CMM takes a short time, hence the measurement variation can considered to be solely the surface contribution. In contrast, on the machine tool, the drift might contribute to the inaccuracies of the surface measured in different directions since the measurement was conducted over a longer period of time. Disregarding the drift through pooled standard deviations calculations surface wetness does not have observable effects on probing measurements. Machine tool's cutting fluid spraying system may affects the thermal state of the spindle during the measurements. Thus, it can also affect the accuracy of the probing measurement. The repeatability of the probe contribute a substantial amount of inaccuracy in the measurements when the drift is included, but pooled standard deviation shows that without the drift probe has repeatability below $1 \mu \mathrm{m}$ measurement along X-, Y-, Z-, 2D- and 3D-directions, respectively. The worst case is the repeatability for the Y-axis measurement with 
a standard deviation of $4.9 \mu \mathrm{m}$ while the 3D measurement has unexpectedly lower standard deviation of $0.6 \mu \mathrm{m}$. Out of sphericity of the probing results was significant at $8.1 \mu \mathrm{m}$.

\title{
Acknowledgements
}

This research work is funded by NSERC, CRIAQ, Pratt \& Whitney Canada, Meloche Group and SONACA Montreal. The authors are very grateful for the experimental support of Guy Gironne and Vincent Mayer.

\author{
Manuscript received by Editorial Board, October 29, 2015; \\ final version, July 05, 2016.
}

\section{References}

[1] R. Guiassa, J.R.R. Mayer, M. Balazinski, S. Engin, F.E. and Delorme. Closed door machining error compensation of complex surfaces using the cutting compliance coefficient and onmachine measurement for a milling process. International Journal of Computer Integrated Manufacturing, 27(11):1022-1030, 2014.

[2] P.A. Cauchick-Miguel, T.G. and Kings. Factors which influence CMM touch trigger probe performance.International Journal of Machine Tools and Manufacture, 38(4):363-374, 1998.

[3] A. Wozniak and M. Dobosz. Factors influencing probing accuracy of a coordinate measuring machine. IEEE Transactions on Instrumentation and Measurement, 54(6):2540-2548, 2005.

[4] M. Dobosz and A. Wozniak. CMM touch trigger probes testing using a reference axis. Precision Engineering, 29(3):281-289, 2005.

[5] A. Wozniak and M. Dobosz. Influence of measured objects parameters on CMM touch trigger probe accuracy of probing. Precision Engineering, 29(3):290-297, 2005.

[6] R.P. Johnson, Q. Yang and C. Butler. Dynamic error characteristics of touch trigger probes fitted to coordinate measuring machines. In Proceedings of Instrumentation and Measurement Technology Conference, pages 1168-1172, St. Paul, MN, USA, 18-21 May 1998.

[7] R.R. Fesperman, S.P. Moylan and Donmez. Methods, practices, and standards for evaluating on-machine touch trigger probing of workpieces. In Proc. 25th Annual Meeting of the American Society for Precision Engineering, ASPE 2010, pages 309-312, 2010.

[8] Test code for machine tools-Part 10: Determination of measuring performance of probing systems of numerically controlled machine tools, ISO/DIS 230-10, 2011.

[9] M. Jankowski, A. Wozniak, and M. Byszewski. Machine tool probes testing using a moving inner hemispherical master artefact. Precision Engineering, 38(2):421-427, 2014.

[10] M.R. Verma, E. Chatzivagiannis, D. Jones and P.G. Maropoulos. Comparison of the measurement performance of high precision multi-axis metal cutting machine tools. In Proc. International Conference on Digital Enterprise Technology - DET 2014 Disruptive Innovation in Manufacturing Engineering towards the 4th Industrial Revolution, Procedia CIRP, 25:138-145, 2014.

[11] M.M. Rahman and J.R.R. Mayer. Five axis machine tool volumetric error prediction through an indirect estimation of intra and inter axis error parameters by probing facets on a scale enriched uncalibrated indigenous artefact. Precision Engineering, 40:94-105, 2015. doi:10.1016/j.precisioneng.2014.10.010. 


\title{
Badania dokładności pomiarów elektrostykową sondą przełączającą na obrabiarkach pięcioosiowych
}

\author{
Streszczenie
}

Elektrostykowe sondy przełączające grają istotną rolę we współczesnej metrologii z uwagi na ich zwartą i silną konstrukcję, odporność na uszkodzenia, długowieczność i doskonałą powtarzalność. Obok zastosowań we współrzędnościowych maszynach pomiarowych (CMM), sondy te są wykorzystywane do wyznaczenia położenia przedmiotu obrabianego na obrabiarce i oceny dokładności obrabiarek. Tak więc, dokładność pomiaru jest sprawą istotną dla użytkowników. Do powstawania niedokładności pomiaru przyczynia się sama sonda, a także powierzchnia pomiarowa, obrabiarka, środowisko pomiarowe itp. $\mathrm{W}$ artykule przedstawiono wpływ nierówności powierzchni, wilgotności powierzchni powodowanej obecnością chłodziwa i kierunku sondowania na dokładność pomiaru na obrabiarce. 